\title{
Presentación. \\ Competitividad urbana: alcances y desafíos
}

Desde las últimas décadas del siglo pasado la competitividad urbana se transformó en un componente básico de la gestión pública de un número creciente de ciudades en diversas partes del mundo. Este hecho, que representa un radical cambio de orientación y contenido de la gestión urbana, con respecto a la que había predominado durante buena parte del período precedente, se produjo bajo el impacto de los avances de la revolución informacional y de la liberalización económica; uno de los hechos distintivos de mayor relevancia fue que en este proceso ganó predicamento la convicción de que el objetivo central de las políticas urbanas debía apuntar hacia el crecimiento económico de las ciudades respectivas, entendido ello como un requisito para mejorar el empleo y las condiciones de vida de sus ciudadanos.

En ese escenario, buena parte de las administraciones urbanas en distintos lugares del mundo comenzaron a implementar políticas orientadas a aumentar el atractivo de sus ciudades, como medio para atraer el mayor volumen posible de los capitales en movimiento en pos de ámbitos capaces de ofrecer mejores condiciones para su reproducción. En lo fundamental, en tanto se podía comprobar que los capitales móviles, que traspasaban incesante e incontrolablemente unas fronteras nacionales cada día más permeables, dotados además de una creciente autonomía para escoger sus lugares de destino, numerosas administraciones urbanas se inclinaron por concebir y aplicar políticas orientadas a fortalecer las ventajas de sus respectivas ciudades para la mejor valorización de esos capitales.

Esto significó la afirmación de un tipo de gestión en el que, como señaló Harvey, una modalidad de corte gerencial predominante durante buena parte del siglo pasado, ha sido desplazada por un enfoque de gobernanza basado cada vez más en criterios de carácter empresarial. El contenido esencial de esta transición, comportó un sustantivo cambio de los objetivos de la gestión urbana, tal como reconoce y justifica un reciente estudio de la Organización para la Cooperación y el Desarrollo Económico, "[...] la política de acondicionamiento del territorio ha pasado del gerencialismo, que busca ante todo proveer con eficacia a todos los ciudadanos de los servicios de utilidad colectiva, al empresarialismo, que se caracteriza netamente por una aproximación estratégica que busca el crecimiento económico, favorable a la toma de riesgo, a la innovación y propenso a orientarse hacia el sector privado" (OCDE, 2007).

Mas allá de la controversia teórica acerca de si son las ciudades o las empresas las que compiten, se puede observar que es un hecho que a medida que este enfoque se fue imponiendo, una cantidad cada día mayor de administraciones urbanas pusieron en competencia a sus ciudades, o a partes de las mismas; en esa dirección, para promoverlas en el contexto de una red de ciudades en proceso de globalización se empeñaron en diseñar y desplegar diversos tipos de estrategias de marketing urbano. 
Al mismo tiempo, como expresión de la importancia adquirida por estas estrategias, diversas entidades privadas han comenzado a realizar estudios, tanto de cobertura internacional como nacional, con el propósito de medir la competitividad de las ciudades en distintas partes del mundo, estudios éstos que han logrado influir en las propias estrategias de competitividad; en efecto, desde que estos estudios se sustentan en la identificación de diversos factores que consideran como condicionantes de los correspondientes niveles de competitividad de cada ciudad analizada, en los hechos dichos factores pasan a ser considerados como aspectos claves para el éxito de las políticas respectivas. Quiere esto decir, que sea cual sea la rigurosidad de esos estudios, que en muchos casos resulta sumamente cuestionable, buena parte de los factores que ellos identifican como factores de competitividad, pasan a influir fuertemente tanto en las políticas urbanas, como también en el comportamiento locacional de los inversores internacionales y en las decisiones de los viajeros globales.

Aun cuando las estrategias urbanas de competitividad suelen estar asociadas a objetivos de cohesión social, hasta ahora no se dispone de evidencia empírica que valide el supuesto de que un aumento significativo de la competitividad urbana se traduzca necesariamente en una mejor calidad de vida y/o un aumento de la cohesión social en la ciudad respectiva. La experiencia de resultados de aplicación de estrategias de esta naturaleza en algunas ciudades ubicadas en países de menor desarrollo relativo, no exhiben todavía resultados excesivamente auspiciosos tanto en términos sociales como ecológicos, por lo que se hace necesario seguir desarrollando investigaciones en esta materia.

No obstante, aun así el tema de la competitividad urbana continúa adquiriendo relevancia en diversas partes del mundo, donde un buen número de ciudades latinoamericanas ya han desplegado importantes esfuerzos en esta dirección. Ha sido ante esta situación que EURE decidió dedicar un número especial a este tema, donde un conjunto seleccionado de trabajos cubre distintos aspectos de las discusiones actuales sobre esta materia y aporta antecedentes para continuar reflexionando sobre las implicancias y los desafíos que plantea esta importante cuestión.

Al presentar este número, EURE deja constancia que los integrantes del Proyecto FONDECYT 1085257 "Santiago de Chile: una ciudad atractiva para un país competitivo", brindaron una valiosa colaboración para la selección y evaluación de los trabajos que aquí se presentan. 


\section{Referencias bibliográficas}

Harvey, David (1989), From Managerialism to Entrepreneurialism: The Transformation in Urban Governance in Late Capitalism. Geografiska Annaler. Series B, Human Geography, v. 71, n. 1, pp. 3-17.

OCDE (2007), Villes et competitivité. Un nouveau paradigme entrepreneurial pour l'amenagement du territoire. París, OCDE. p. 7. 
